\title{
O uso comercial do conhecimento tradicional: a venda de "fetiches" bateke à expedição de Frederick Starr em Leopoldville (1905) ${ }^{\mathrm{I}}$
}

Paulo Roberto Marques de Oliveira

\section{Resumo}

Este artigo busca compreender alguns aspectos da comercialização de "fetiches" entre os Bateke e a expedição de Frederick Starr na estação de Leopoldville no ano de I905, utilizando como fontes dois dos diários de campo redigidos por Starr. Por meio de uma leitura crítica deles, foi possível entender as intenções que se colocaram durante o momento da compra e venda dos "fetiches". Essas intenções provinham tanto do antropólogo estadunidense quanto dos Bateke, que decidiram por vontade própria vender artefatos de sua cultura de origem. Empregando a perspectiva da história social, foi possível devolver a historicidade às referidas relações comerciais e constatar que, em grande parte delas, os centro-africanos conseguiram tirar vantagens sobre Frederick Starr e sua expedição. Palavras-chave: África Central - Estado Independente do Congo - Bateke Leopoldville - Frederick Starr.

I As reflexões desenvolvidas neste texto fazem parte de uma pesquisa intitulada "'Os maiores de toda a África equatorial': rastros e registros do contato dos Bakuba com as expedições ocidentais, I884-I909 (Atual República Democrática do Congo)" e que foi orientada pela Profa. Dra. Livre-docente Maria Cristina Cortez Wissenbach. Essa investigação contou com o financiamento do Conselho Nacional de Desenvolvimento Científico e Tecnológico ( $\mathrm{CNPq}$ ) do Brasil por meio da concessão de uma bolsa de iniciação científica do Programa Institucional de Bolsas de Iniciação Científica (Pibic) da Universidade de São Paulo (USP) do edital 20I5/20I6. 


\section{O esforço para uma história das sociedades centro- -africanas}

Frederick Starr tornou-se um dos maiores divulgadores do conhecimento antropológico no início do século XX a partir de suas diversas publicações. Diferentemente de seu contemporâneo Franz Boas, o pai da antropologia estadunidense, que profissionalizou esse campo do conhecimento, Starr foi um artesão no ofício dedicado à produção de conhecimento sobre diferentes partes do planeta. Em nome do American Museum of Natural History (New York), liderou, conjuntamente com o missionário presbiteriano Samuel Philips Verner, uma expedição para recolha de material etnográfico no Estado Independente do Congo entre os anos de I905 e I906. Ao todo, a coleção obtida nesse empreendimento perfaz 4.863 peças, hoje lotadas no referido museu estadunidense.

Neste texto, dedicamo-nos a perscrutar um recorte da trajetória de Frederick Starr ao Estado Independente do Congo, atentando-nos, sobretudo, para suas relações pessoais com as sociedades centro-africanas na estação de Leopoldville. A documentação trabalhada consiste em dois diários de campo pertencentes à University of Chicago Library que estão disponíveis no banco de dados on-line do American Museum of Natural History.

Nosso objetivo com este esforço intelectual é realizar uma leitura crítica dessa documentação e uma problematização das relações sociais estabelecidas entre os indivíduos centro-africanos e a expedição chefiada por Starr para que entendamos que a agência centro-africana foi essencial para essa expedição e que, sem ela, o empreendimento não teria conseguido realizar seus objetivos.

Tratar das relações comerciais entre os centro-africanos e a referida expedição é, de alguma forma, contribuir para o esforço de devolver a historicidade a essas sociedades. Essa tarefa vem sendo realizada por diferentes obras, como os trabalhos sobre as populações lunda² abordadas por Márcia Cristina Almeida (20I3) e Elaine Ribeiro (20I3) (Universidade Federal de Alfenas); sobre os Vili, em Jill Dias ([2002] 2007); sobre os Chokwe e os Mbangala, em Beatrix Heintze ([2002] 2004) (Frobenius-Institut) e Isabel de Castro Henriques (2003) (Universidade de Lisboa); e, na perspectiva de pensar o Atlântico como um espaço de relações que interconectavam diferentes con-

2 Grafamos, como em Antropologia, os etnômios que são substantivos com letra maiúscula e os adjetivos com minúscula. Adotamos também o hábito de não flexionar para o plural os etnômios quaisquer que sejam. 
tinentes, sociedades e grupos sociais, consideramos as publicações de Maria Gristina Cortez Wissenbach (20II; 20I5) (Universidade de São Paulo).

No entanto, a força do imaginário ocidental construído numa longa duração e que consagrou ao continente africano a imagem de uma região uniformemente primitiva, hostil e apenas útil no fornecimento de matéria-prima ainda é grande (OLIVA, 2OIO). Faz-se necessário, portanto, um esforço intelectual coletivo e também de longa duração para desconstruir esse imaginário que inferioriza o continente africano, estabelecendo um conhecimento que valorize não só a África na atualidade, mas em sua perspectiva histórica, levando em conta sua pluralidade de culturas.

Tendo isso em vista, decidimos nos inserir nesse esforço intelectual coletivo. Optamos por tentar entender pelo menos uma fração da experiência histórica centro-africana a partir da perspectiva da história social apresentada por E. P. Thompson em sua obra A miséria da teoria ([I978] I98I). Nela, o autor apresenta o conceito de experiência, que seria "a resposta mental e emocional, seja de um indivíduo ou de um grupo social, a muitos acontecimentos inter-relacionados ou a muitas repetições do mesmo tipo de acontecimento" (THOMPSON, [I978] I98I, p. I5). Dessa forma buscamos, neste texto, tentar captar as repostas que os centro-africanos deram aos acontecimentos com os quais viveram a partir das relações de compra e venda de artefatos entre eles e a expedição de Frederick Starr. Nosso trabalho, portanto, foi duplo: dar uma maior complexidade ao contexto da aquisição das peças que hoje estão lotadas no American Museum of Natural History e tentar entender a agência histórica centro-africana durante o domínio colonial, fugindo da chave interpretativa da sujeição e da subordinação dessas sociedades. Gremos, na verdade, que, mesmo quando parecia que os ocidentais tinham tudo sob controle, a agência africana conseguiu conquistar pequenas melhorias que, por muito tempo, haviam sido ignoradas pela historiografia.

\section{As relações comerciais com a expedição de Frederick Starr}

Frederick Starr chegou à estação de Leopoldville no dia 24 de novembro de I905 por meio da linha férrea que partia de Matadi. Foi recebido pelo Sr. Morgan, um oficial a serviço do rei dos belgas na região, e seu serviçal M'Pere, um centro-africano que não sabia sua origem já que fora retirado de sua aldeia natal há bastante tempo e há mais de quinze anos servia aos brancos na referida estação (UNIVERSITY OF GHIGAGO LIBRARY, I905b). 
O trajeto por trem fora tranquilo; Starr necessitava apenas de um pequeno descanso. Dessa forma, o dia seguinte ficou reservado para isso. No dia 26 , iniciou seu trabalho etnográfico já com todo o material em ordem. Naquele momento, sua expedição contava com apenas um homem, Manuel, que lhe servia de intérprete e carregador ao mesmo tempo e foi com ele que Starr se dirigiu às aldeias próximas a Leopoldville, efetuou suas compras da produção material local, fotografou o que achou interessante e redigiu suas notas em seus diários (UNIVERSITY OF CHICAGO LIBRARY, I905a; I905b).

Frederick Starr havia se preparado para o trabalho de campo que realizaria. Visitara, por exemplo (segundo as denominações registradas em seus diários), o Brussels Ethnographic Museum e sua biblioteca, o Museum of Natural History em Bruxelas e o Congo Museum (que acreditamos que seja o Musée Royal de l'Afrique Centrale). Seus estudos, nessas instituições, percorreram diferentes temas, como a preparação dos mortos e as roupas funerárias, a linguagem gestual, a linguagem dos tambores, rituais de iniciação e as sociedades secretas da região centro-africana (UNIVERSITY OF CHICAGO LIBRARY, I905b).

Em Leopoldville, Starr deparou-se com os Bateke, que demonstraram uma grande receptividade. Muitos indivíduos deslocaram-se de suas aldeias de origem e vieram à presença do antropólogo vender-lhe alguns artefatos típicos de sua cultura. Acreditamos que essa abertura para o diálogo com o Outro na cultura teke seja fruto de uma relação de acontecimentos provenientes da aproximação dos Bateke com o comércio atlântico de escravos e do contexto do final do século XIX para a região.

Organizadores e dirigentes de expedições comerciais ao reino do Kongo desde o século XVI, os Bateke ou Teke ficaram conhecidos pela exportação, sobretudo de marfim e escravos para a América portuguesa (PINÇON, I999). A presença teke na América ficou sob a denominação da nação diaspórica Monjolo representada, por exemplo, na Voyage pittoresque et historique au Brésil de Jean Baptiste Debret (I835). O crescimento econômico dos comerciantes ligados ao Atlântico acentuou uma clivagem na sociedade teke entre aqueles que detinham o poder econômico e aqueles relacionados ao poder político-religioso. Essa situação conflitiva provocou, em meados do século XVIII, uma reorganização social em torno dessa nova elite. Aqueles que governavam por deter os saberes da manipulação das forças naturais perderam espaço para os indivíduos ligados às redes de comércio de longa distância. No século XIX, acentuou-se o papel dessa elite econômica que se voltara, a partir de então, principalmente, para o comércio de marfim (PINÇON, I999).

Acreditamos que a reestruturação da sociedade teke em torno de uma elite ligada ao comércio atlântico contribuiu para a penetração mais rápida 
do impacto cotidiano da presença ocidental. Essa presença era proveniente tanto da proliferação de viajantes, que durante a segunda metade dos Oitocentos, interagiram com a região, quanto da ação dos representantes do poderio colonial, sobretudo aqueles ligados à construção dos caminhos férreos do Estado Independente do Congo e que, com suas promessas, propiciaram uma intensa imigração para as terras teke, principalmente de populações de origem kongo (DUPRÉ; FÉAU, I999). A intensa circulação de pessoas no território acabou por fortalecer o papel do comércio na região. A atividade comercial era capaz de interligar e colocar em diálogo diferentes culturas e interesses distintos no ato de compra e venda, estabelecendo uma espécie de linguagem comum, na qual a negociação entre as partes ganhou um papel cada vez maior. As relações comerciais na região envolviam diversas pessoas de várias partes da África Central, o que representava, cada vez mais, um problema para os recortes territoriais estabelecidos pelas potências europeias no final do século XIX.

Mesmo após as tentativas do governo colonial para tentar "impedir e combater energicamente" o comércio caravaneiro (HEINTZE, [2002] 2004, p. 350), Frederick Starr presenciou, em Leopoldville, artefatos e ações típicas desse comércio de longa distância (UNIVERSITY OF CHIGAGO LIBRARY, I905b), como os pacotes de sal em formatos específicos que antes provinham de Angola, Cassanje e da Lunda (HEINTZE, [2002] 2004). Essas relações comerciais eram respaldadas entre as sociedades locais por uma história que, no início do século XX, completava cerca de duas décadas.

O comércio de longa distância com paradas obrigatórias na região que enquadrava Leopoldville iniciou-se na década de I880, quando se encerrou a "rota meridional para a Mussumba, em virtude da desestabilização da 'Commonwealth' [3] lunda e dos conflitos militares entre Lunda e Chokwe" (HEINTZE, [2002] 2004, p. 332). Observou-se, no período, "um deslocamento de quase todo o comércio distante da Angola portuguesa em direção ao Norte e ao Nordeste", abarcando locais como Cabau, um mercado kuba em território kete, e Muquengue (na verdade, Calamba Muquengue), a capital do território luluwa que sofreu profundas transformações a partir da década de 1870 com o comércio chokwe e ambaquista na região (HEINTZE, [2002] 2004).

3 Em tradução livre, seria "comunidade". Termo, segundo Heintze, sugerido por Vansina em seu artigo intitulado "Government in Kasai before the Lunda", que foi publicado no International Journal of African Historical Studies (3I,I) em I998 (p. I-22) (Cf. nota II, HEINTZE, [2002] 2004, p. 44). 
Não devemos nos esquecer de que o comércio caravaneiro, além de envolver produtos, colocou em contato diversos conhecimentos e indivíduos de culturas distintas como bem aponta Beatrix Heintze ([2002] 2004) em Pioneiros africanos: caravanas de carregadores na África Centro-Ocidental (entre 1850-189o). Como esse comércio tornou-se um elemento central para diversas sociedades centro-africanas, não é de se estranhar sua permanência durante a implementação do colonialismo no continente. A sua centralidade permeava grande parte das relações sociais, o que pode ser evidenciado tanto pela "especialização" de indivíduos (DIAS, [2002] 2007; HEINTZE, [2002] 2004; HENRIQUES, 2003; WISSENBACH, 20I5), como pelo desejo de se relacionar comercialmente com as expedições dos ocidentais na região, por exemplo, a de Frederick Starr.

Os diários de campo do antropólogo estadunidense permitem-nos, por meio de sua leitura crítica, compreender as relações sociais estabelecidas entre as sociedades locais e sua expedição. Optamos, neste texto, por trabalhar o recorte correspondente à permanência de Starr na estação de Leopoldville, ou seja, de 24 de novembro a 5 de dezembro de I905. Nesses doze dias, Starr adquiriu 43 artefatos, dos quais 37 por meio de compra. Despendeu 6I, 25 francos belgas (BEF) para adquiri-los. Mais da metade desses artefatos (58, I4\%) eram o que o viajante comumente denominou de "fetiche", que seriam, em sua concepção, objetos mágico-religiosos que, por conterem substâncias orgânicas e serem manipulados em rituais, possuíam uma relação com as forças do mundo invisível. Sob esse rótulo encontravam-se artefatos dos mais variados aspectos morfológicos, como estatuetas, conchas, potes, jarros, pacotes de fibra vegetal e chifres amarrados a penas.

A partir da análise da documentação correspondente a Leopoldville, chegamos a um resultado que abre horizonte para o prosseguimento das pesquisas sobre os relatos da expedição de Frederick Starr ao Estado Independente do Congo. Constatamos que a agência das sociedades centro-africanas é evidente e constantemente expressa na documentação, por exemplo por meio da menção a indivíduos que trouxeram um grande volume de artefatos de seu grupo cultural para negociar sua venda com a expedição de Starr. Essa agência, que dialoga positivamente com o objetivo da expedição (a coleta de material etnográfico), foi indispensável para que a missão atingisse seus propósitos na estação de Leopoldville. Isso fica claro quando vemos que 65, I2 \% dos artefatos adquiridos provieram da iniciativa dos centro-africanos, que ficaram sabendo que Starr estava interessado em sua produção material e vieram à sua presença (Tabela 2), e que 62,5\% das relações comerciais estabelecidas em Leopoldville deram-se com esses indivíduos (Tabela I). 
Tabela I - Iniciativa nas relações comerciais em Leopoldville

\begin{tabular}{|c|c|c|}
\hline Iniciativas nas relações & Quantidade de relações & Porcentagem \\
\hline Ocidentais na região & I & $6,25 \%$ \\
\hline Expedição de Frederick Starr & 5 & $3 \mathrm{I}, 25 \%$ \\
\hline Gentro-africanos & IO & $62,5 \%$ \\
\hline Total & I6 & I00\% \\
\hline
\end{tabular}

Fonte: Elaboração própria (20I6) a partir de University of Chicago Library (I905a; I905b).

\section{Tabela 2 - Proveniência dos artefatos em relação à iniciativa nas relações comerciais}

\begin{tabular}{|c|c|c|}
\hline Iniciativas nas relações & Quantidade de artefatos & Porcentagem \\
\hline Ocidentais na região & 6 & $\mathrm{I} 3,95 \%$ \\
\hline Expedição de Frederick Starr & 9 & $20,93 \%$ \\
\hline Gentro-africanos & 28 & $65, \mathrm{I} 2 \%$ \\
\hline Total & 43 & $100 \%$ \\
\hline
\end{tabular}

Fonte: Elaboração própria (20I6) a partir de University of Chicago Library (I905a; I905b).

Outra constatação à qual chegamos foi a de que os centro-africanos estabeleceram relações com Starr e sua expedição a partir de seus interesses próprios, seja pelo fato de ele estar ligado ao poderio colonial na região, seja por ele estar interessado em comprar sua produção material. A venda e, por conseguinte, a compra foram encaradas neste trabalho como um momento no qual os dois lados deixaram expressas suas intenções (comprar ou vender), disputaram o valor (negociação) e, por fim, consumaram a relação comercial. Portanto, ao afirmar isso, colocam-se Starr e as sociedades locais numa relação horizontal em que a negociação poderia beneficiar qualquer um dos lados. Porém, quem sobressaiu na maior parte das situações foram os centro-africanos.

Starr despendeu 49,5 BEF com os indivíduos que o procuraram por suas próprias vontades (Tabela 3 ). Este dado per se nada diz, já que $65,12 \%$ dos artefatos provieram das iniciativas centro-africanas, e seria quase uma consequência imediata o valor nesses casos ser maior do que o das relações comerciais que partiram da iniciativa de Starr e de sua expedição, que lhe exigiram apenas II, $75 \mathrm{BEF}$. No entanto, o valor médio, ou seja, resultado da razão 
Tabela 3 - Valor despendido em relação à iniciativa nas relações comerciais em Leopoldville

\begin{tabular}{|c|c|c|}
\hline Iniciativas nas relações & Valor & Porcentagem \\
\hline Ocidentais na região & $\circ \mathrm{BEF}^{*}$ & 0, $\% \%$ \\
\hline Expedição de Frederick Starr & $\mathrm{II}, 75 \mathrm{BEF}$ & $\mathrm{I} 9, \mathrm{I} 8 \%$ \\
\hline Centro-africanos & $49,5 \mathrm{BEF}$ & $80,82 \%$ \\
\hline Total & $\mathbf{6 I , 2 5} \mathbf{B E F}$ & $\mathbf{1 0 0 \%}$ \\
\hline
\end{tabular}

Fonte: Elaboração própria (20I6) a partir de University of Chicago Library (I905a; I905b).

entre o montante pago e a quantidade dos artefatos, aponta que as relações que partiram da iniciativa centro-africana exigiram de Starr um preço maior (I,77 BEF/artefato) do que o que o antropólogo geralmente pagava quando a relação comercial partia de sua intenção (I,3 BEF/artefato).

Porém, isso não é afirmar que as relações comerciais para os centro-africanos visavam apenas ao lucro. Isso fica mais claro quando nos debruçamos sobre a variação do valor dos "fetiches" vendidos pela iniciativa centro-africana (Gráfico I).

O gráfico a seguir possui, num dos eixos, o valor pago e, no outro, os artefatos dispostos cronologicamente. Percebe-se, a princípio, que os preços foram decaindo. Essa constatação poderia abrir espaço para a hipótese de que, ao longo de sua convivência no interior do continente, os integrantes da expedição de Starr aprenderam a se relacionar comercialmente com as populações locais e, consequentemente, a pagar menos pelos produtos que compravam. No entanto, nosso percurso foi outro. Decidimos materializar os dados do gráfico na trama social e entender as relações comerciais estabelecidas em seus respectivos contextos.

Por meio de uma análise centrada nas relações comerciais que envolveram os chamados "fetiches", percebemos que a variação de seu preço está, geralmente, atrelada a um fator: se a peça possuía ou não informações sobre seu uso social. Quase todas aquelas que no gráfico possuem seu valor igual ou maior que 2 BEF possuem informações desse tipo, com a exceção de AMNH 90.0/ 6368, AMNH 90.0/ 7746 e AMNH 90.0/ 9830, adquiridas numa mesma relação comercial da qual trataremos adiante. O uso social desses artefatos variava bastante e sua forma (estatueta, pote, concha ou uma trouxinha amarrada) dava indícios de sua função.

* Todos os artefatos adquiridos em Leopoldville por iniciativas de ocidentais que procuraram Frederick Starr e sua expedição foram presentes, por isso não lhe exigiram nenhuma despesa para a aquisição. 
Gráfico I - Valor dos "fetiches" adquiridos nas proximidades de Leopoldville

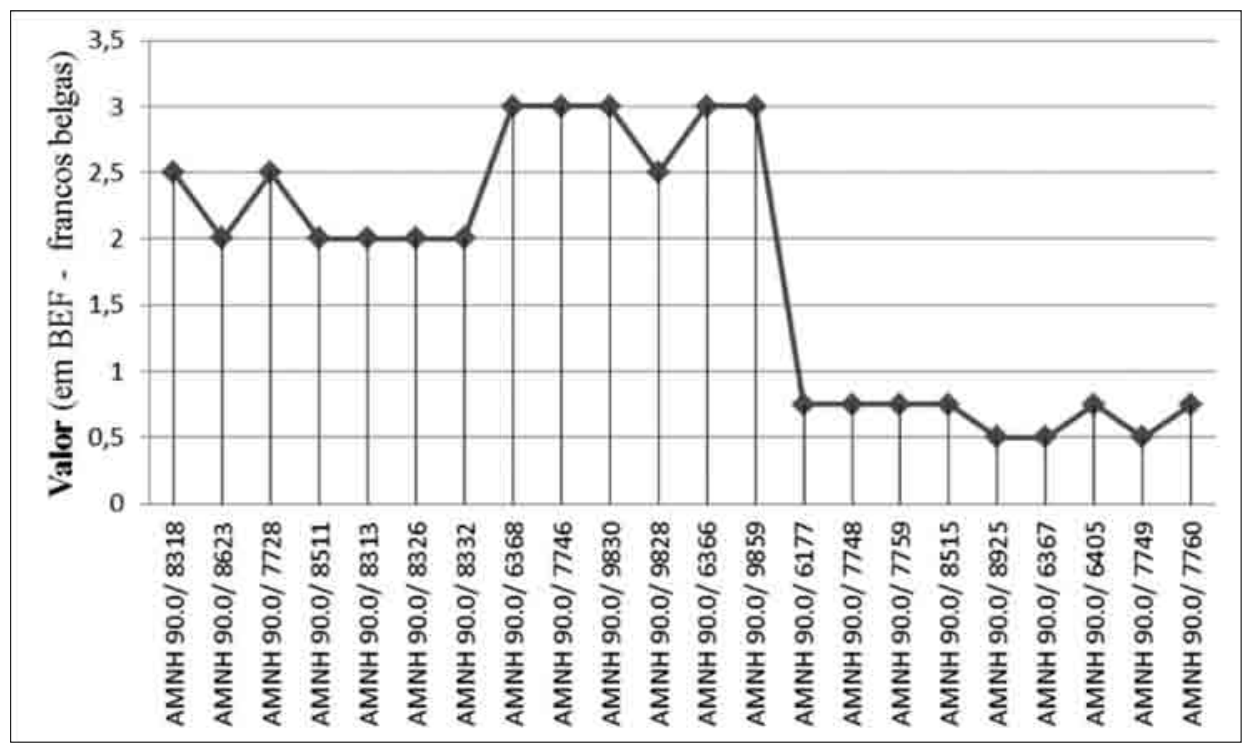

Fonte: Elaboração própria (20I6) a partir de University of Chicago Library (I905a; I905b).

Em Leopoldville, Frederick Starr comprou "fetiches" para sucesso na caça (AMNH 90.0/ 83I8 e AMNH 90.0/ 9828) e nas relações comerciais (AMNH 90.0/ 8623); para proteção após ingestão de algo que lhe poderia ser prejudicial, como comida estragada ou enfeitiçada (AMNH 90.0/ 7728 e AMNH 90.0/ 85II); para a proteção contra bruxas (AMNH 90.0/6366); e para que, quando andasse "em noites escuras através da floresta", não fosse picado por cobras venenosas (AMNH 90.0/ 9859) (UNIVERSITY OF CHICAGO LIBRARY, I905b, p. II8-9, tradução nossa). Esses artefatos não foram usados pelo antropólogo, mas, segundo seus vendedores, já haviam sido utilizados com sucesso pelos seus antigos possuidores.

As informações sobre esses objetos permaneceram até os dias atuais, por meio das informações orais dos centro-africanos relatadas a Starr no momento da venda, que foram registradas em seus diários de campo. No entanto, no próprio registro escrito, temos elementos que demonstram que as informações das sociedades locais passavam pelos filtros sociais do antropólogo, que exprimia suas opiniões sobre elas. Um caso sintomático é o da venda de quatro "fetiches" no dia 3 de dezembro de I905, no qual dois vendedores bateke afirmaram que seus fetiches-conchas (AMNH 90.0/ 7748 e AMNH 90.0/ 7759) 
eram para proteção contra búfalos. Starr escreveu em seu diário de campo que aquilo era insuficiente e negociou com os Bateke o valor de seus quatro artefatos apresentados, que foram vendidos em lote por $3 \mathrm{BEF}$, ou seja, cada um custando 0,75 BEF (UNIVERSITY OF CHICAGO LIBRARY, I905b). Esse preço era bem inferior ao das outras peças adquiridas até então.

Porém, afirmamos que o preço dos "fetiches" não estava subordinado apenas ao desejo de Starr nas informações acerca do uso social dos artefatos, mas também sujeito às habilidades de negociação de cada uma das partes interessadas na relação comercial. No dia 2 de dezembro de I905, um Muteke ${ }^{4}$ veio até a casa de Frederick Starr e trouxe três "fetiches" para vender-lhe (AMNH 90.0/6368, AMNH 90.0/ 7746 e AMNH 90.0/ 9830). Não apresentou nenhuma informação sobre seus objetos e, mesmo assim, conseguiu vendê-los ao maior preço registrado para o recorte de Leopoldville: 9 BEF pelo lote, ou seja, 3 BEF por cada peça. Frederick Starr escreveu em seu diário sobre essa relação: "Nós conseguimos garantir o lote por 9 francos, embora sem qualquer informação" (UNIVERSITY OF CHICAGO LIBRARY, I905b, p. II5 et seq., tradução nossa). Isso mostra que as habilidades de negociação do antropólogo conseguiram apenas reduzir para 9 BEF o preço dos três "fetiches" e, como desejava comprá-los, teve de ceder às exigências do Muteke possuidor das peças que, provavelmente, não deixaria que os preços diminuíssem. Essa negociação deve ter sido difícil, do contrário Starr não teria colocado a aquisição como uma tarefa concluída com sucesso ("[...] conseguimos garantir [...]") mesmo sem ter obtido nenhuma informação sobre o uso social daqueles artefatos.

Podemos concluir que o conhecimento sobre o uso social dos artefatos (logo, o conhecimento proveniente da tradição das populações locais) foi utilizado pelas sociedades africanas para valorizar suas mercadorias quando negociavam com Frederick Starr, que era interessado nessas informações. Dessa forma, ao relatarem esses dados conseguiam mais argumentos quando chegava o momento da negociação. Aqueles que não queriam dizer ou que de fato não sabiam a procedência de seus objetos eram obrigados a utilizar uma maior habilidade para as relações comerciais, o que ficou registrado nos casos de 2 e 3 de dezembro de 1905 .

Os resultados apresentados neste texto, na verdade, constituem-se de guias para o prosseguimento das pesquisas sobre os relatos de Frederick Starr ${ }^{5}$.

4 Indivíduo teke.

5 As análises sobre a documentação da expedição de Starr ao Estado Independente do Congo estão em 
Análises como estas devem ser feitas para toda a documentação da expedição desse antropólogo, tendo em mente as especificidades de cada região visitada. Dessa forma, poderemos fazer generalizações maiores sobre a agência das sociedades centro-africanas no Estado Independente do Congo e perceber que, mesmo no período da instalação colonial, a ação africana não se resumiu à confrontação direta, mas também a situações de negociação nas quais as sociedades locais tiveram de se colocar como interlocutoras dos dominadores estrangeiros e barganhar com eles os preços de seus produtos e as condições de seus trabalhos e de suas vidas (RIBEIRO, 20I3).

\section{Referências}

ALMEIDA, Márcia C. P. F. Comércio, bens de prestígio e insígnias de poder: interfaces entre cultura material e as agências centro-ocidentais africanas nos relatos de viagem de Henrique de Carvalho em sua expedição à Lunda (I884I888). In: SIMPÓSIO NACIONAL DE HISTÓRIA, 27, 20I3. Natal, Anais Eletrônicos: Associação Nacional de História, 20I3. Disponível em: <http:// www.snh20I3.anpuh.org/resources/anais/27/I37I3362I6_ARQUIVO_ ANPUHMarcia.pdf>. Acesso em 23 mar. 2016.

DEBRET, Jean-Baptiste. Esclaves nègres, de diffèrentes nations; Diffèrentes nations nègres. In: Voyage pittoresque et historique au Brésil, ou Séjour d'un artiste français au Brésil, depuis I8I6 jusqu' en I83I inclusivement, epoques de l'avènement et de l'abdication de S. M. D. Pedro Ier, fondateur de l'Empire brésilien. Dédié à l'Académie des Beaux-Arts de l'Institut de France, Tome Second. Paris: Firmin Didot Frères, I835.

DIAS, Jill. Novas identidades africanas em Angola no contexto do comércio atlântico. In: BASTOS, Gristina; ALMEIDA, Miguel Vale de; FELDMAN-BIANCO, Bela (Orgs.). Trânsitos coloniais: diálogos críticos luso-brasileiros. Campinas: Ed. Unicamp, [2002] 2007, p. 315-343.

DUPRÉ, Marie-Glaude; FÉAU, Étienne. Introduction. In: RÉUNION DES MUSÉES NATIONAUX (Ed.). Batéké: peintres et sculpteurs d'Afrique Centrale. Paris: Musée National des Arts d'Afrique et d'Océanie, I999.

curso. Elas fazem parte de uma pesquisa intitulada "Comércio, conhecimento e cultura: as sociedades centro-africanas no início do século XX a partir dos testemunhos de Frederick Starr" (orientação profa. Dra. Livre-docente Maria Cristina Cortez Wissenbach) e que conta com o financiamento do GNPq por meio da concessão de uma bolsa de iniciação científica por meio do edital 20I6/20I7 do Pibic da USP. 
HEINTZE, Beatrix. Pioneiros africanos: caravanas de carregadores na África Centro-Ocidental (entre I850-I890). Tradução de Marina Santos. Lisboa: Caminho, [2002] 2004 (Coleção Estudos Africanos).

HENRIQUES, Isabel de Castro. Armas de fogo em Angola no século XIX. In: . Os pilares da diferença: Portugal-África, séculos XV-XX. Lisboa: Caleidoscópio, 2003, p. 365-39I.

OLIVA, Anderson Ribeiro. Os africanos entre representações: incursões sobre as ideias e reflexos da África no imaginário ocidental. In: Reflexos da África: ideias e representações sobre os africanos no imaginário ocidental, estudos de caso no Brasil e em Portugal. Goiânia: Editora da PUG-Goiás, 2010, p. 47-IO5.

PINÇON, Bruno. Archéologie et histoire. In: RÉUNION DES MUSÉES NATIONAUX (Ed.). Batéké: peintres et sculpteurs d'Afrique Centrale. Paris: Musée National des Arts d'Afrique et d'Océanie, I999.

RIBEIRO, Elaine. Barganhando sobrevivências: os trabalhadores da expedição de Henrique de Carvalho à Lunda, I884-I888. São Paulo: Alameda, 2013.

THOMPSON, Edward Palmer. A miséria da teoria ou um planetário dos erros (uma crítica ao pensamento de Althusser). Tradução de Waltensir Dutra. Rio de Janeiro: Jorge Zahar Ed., [I978] I98I (Coleção Biblioteca de Ciências Sociais - Sociologia).

UNIVERSITY OF CHICAGO LIBRARY. Starr, Frederick: Papers. Research Materials: Field Notes, Africa, I905-I9I2, caixa IO, pasta I. I905a. ${ }^{6}$ [Não publicado] WISSENBACH, Maria Cristina Cortez. As feitorias de urzela e o tráfico de escravos: Georg Tams, José Ribeiro dos Santos e os negócios da África Centro-Ocidental na década de I840. Afro-Ásia, Salvador, n. 43, p. 43-90, $201 \mathrm{I}$.

WISSENBACH, Maria Cristina Cortez. Dinâmicas históricas de um porto centro-africano: Ambriz e o Baixo Congo nos finais do tráfico atlântico de escravos (I840 a I870). Revista de História, São Paulo, n. I72, p. I63-I95, jan.-jun./20I5.

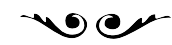

Paulo Roberto Marques de Oliveira é graduando em História pela Universidade de São Paulo. paulorobertomarquesoliveira@gmail.com.

6 Grande parte do material encontrado nos diários pode ser consultada no banco de dados da divisão de Antropologia do American Museum of Natural History em <https://anthro.amnh.org/starr_archive>. Acesso em 23 mar. 2016. 